\title{
Impact of Systematic Assessment of Instruction on Secondary School Students' Physics Achievement at Cognitive Level of Knowledge
}

\author{
Femi Adetunji Adeoye ${ }^{1}$ \\ School of Education \\ National Open University of Nigeria, Lagos, Nigeria.
}

\begin{abstract}
The study examined empirically the impact of systematic and unsystematic assessment of instructions, cognitive style and gender on knowledge of physics concepts among Senior Secondary Two (SS II) Students in Lagos Island Local Government Area of Lagos State, Nigeria. It made use of 120 secondary school two (SS II) students (72 males and 48 females) in a pretest-posttest non-randomized control group design in which treatment systematic assessment at two levels was crossed with two levels of cognitive style and gender. Data analysis involved analysis of covariance and graphical illustration as post-hoc measures. The results indicate that allowing systematic attributes of continuous assessment (CASS) to come into play in physics teaching has significant effect on remembering of physics concepts across all the students' cognitive style-gender groupings. The results also indicate a significant gender-group (in support of females) in remembering of physics concepts. These results show the need for secondary school physics teachers to bring in systematic characteristic of CASS into the assessment of physics teaching. The teachers should also be more patient with male students since their knowledge of physics concepts is significantly lower than that of their female counterparts.
\end{abstract}

Keywords: Systematic Assessment, Achievement, Cognitive Style, Knowledge, Physics.

\section{Introduction}

The foundation for better achievement in physics takes its root from the first year of the senior secondary school. The physics curriculum at this level emphasizes that students must be well developed at the lowest level of cognitive domain i.e. knowledge before that of the other two levels (understanding and thinking) if physics is to be well understood by them at their early introduction of the subject (Adeoye, 2000).

The lack of proper attention to this aspect of the physics curriculum by the respective physics teachers led to students' perception of physics as difficult subject (Onwuioduokit, 1998). This had affected learners' interest (Orji, 1998; Iloputaife \& Nworgu, 2003) and has subsequently led to declining in enrolment and underachievement in physics (Iroegbu, 1998; Orji 1998; Iloputaife \& Nworgu, 2003).

Many empirical studies in Nigeria and abroad have focused on the causes of these problems (Hurd, 1983; Okpala, 1995). However, these studies, despite their scope and depth, only examined the extent to which physics achievement at the general cognitive level could be predicted without absolute attention paid to each of the cognitive levels of knowledge, understanding and thinking (Okpala and Adeoye 1999; Adeoye 2000). This

${ }^{1}$ Correspondin Author, Phone: +2348035029542 ,

E-mail: Feminoun2005@yahoo.com

ISSN: 1306-3049, C2010 
is in spite of all available evidences (Adeoye, 1998; 2000) that knowledge of physics concepts at all levels of education are indeed essential ingredients for developing strong foundations and sound academic achievement in the subject as well as the other higher cognitive levels i.e. understanding and thinking.

The assessment of students regardless of the physics teaching strategies adopted in all the previous studies were not in accordance with the systematic (planned and organized) attribute of continuous assessment (CASS). The procedure used by physics teachers in assessing physics instructions fall short of what contains in the National Policy on Education (FGN, 1998) which directed that educational assessment and evaluation shall be liberalised by their being based in whole or in part on continuous assessment of the progress of the individual.

Continuous assessment according to Okpala, Onocha and Oyedeji (1993) is a system of assessment which is carried out at pre-determined intervals for the purpose of monitoring and improving the overall performance of students and of the teaching/learning environment. CASS is one of the most popular features of the present 6-3-3-4 educational structure in Nigeria. The policy document on this structure prescribes CASS as a substitute for the orthodox one-shot examinations in schools. Mathematics and Science educators (Obe, 1983; Ojerinde and Falayajo, 1984; Okpala and Onocha, 1994; Adeoye, 2000) supported the use of the systematic assessment in assessing students instructions irrespective of the teaching strategies employed. There support was on the basis that it involves planned and organized attributes.

In spite of possible impact of physics instructional strategy (that is characterized by the planned and organized attributes of CASS) on students achievement at the cognitive level of remembering. Research evidences (German 1988; Okpala and Onocha 1995) have shown that a learner characteristic (cognitive style) that is concerned with the ways individuals perceive and process information is a psychological construct which requires individuals to be categorized as either analytic or non-analytic subjects.

Also of interest is the traditional attitude of Nigerian parents in investing more in the education of boys (Onocha, Okpala and Offorma, 1995) at the expense of girls, which results to the paucity of Nigerian girls and women in science and technology (Balogun, 1994; Adeniyi, 1996). In view of this discrimination against one particular sex and its implications in the learning of science, gender became part of the predictor variables of this study.

In all, the researchers contend that the need to improve students' achievement in physics at knowledge level and the fact that a physics instructional method that is characterized by systematic attributes of CASS and some learner characteristics (cognitive style and gender) as predictor variables could influence physics achievement (criterion variable) provide the theoretical basis to posit the problem of this study.

\subsection{Research Questions}

The study sought to provide answers to the following questions

1. Is knowledge of physics concepts significantly influenced by

a. Treatment (systematic and unsystematic attributes);

b. Cognitive style and

c. gender

2. Is knowledge of physics concepts significantly influenced by interaction of:

a. Treatment and cognitive style 

b. Treatment and gender
c. Cognitive style and gender; and
d. Treatment, cognitive style and gender

\section{Methodology}

a) Design: This is a quasi-experimental study that made use of pretest-posttest nonrandomized control group design in which the treatment (at two levels) was crossed with cognitive style (at two levels) and gender (at two levels)

b) Sample: Stratified cluster sampling technique was used to select 120, SS II physics students (72 males and 48 females) from four coo-educational senior secondary schools that are distantly located from each other within Lagos Island Local Government Area of Lagos State, Nigeria. The subjects have varied cognitive style orientation (66 analytical and 54 non-analytical). Their ages ranged from 15 to 19 years (mean age $=17.3$ years; $\mathrm{SD}=0.98)$.

c) Instrumentation: The study involved using the following valid and reliable two instruments

i) Cognitive Style Test (CST) adopted from Adeoye (2000)-Test-re-test reliability value $=0.92$

ii) Physics Achievement Test (PAT) - Prior to the beginning of the experiment, a 40-item, multiple-choice Physics Achievement Test (PAT) was administered to the subjects. The PAT was based on the physics topics selected for the study. Original 65 items in PAT were submitted to an 8-member validation panel composed of 4 experienced secondary school physics teachers, 2 experts in test construction and 2 university lecturers each in physics and English language respectively. Their judgments regarding the extent to which the items were spread to cover the selected topics, language level and cognitive level measured were used to select the final 40 items for PAT.

The PAT was pilot tested using a school in Ikeja Local Government Area of Lagos, which had similar characteristics as the sample schools. This ascertained the test reliability. The reliability coefficient was calculated using Kuder-Richardson formula 21 (KR-21) (Gronlund, 1981). The reliability coefficient of PAT instrument was of 0.91 which rounds of to $\mu=0.9$. According to Fraenkel and Wallen (2000), an $\mu=0.7$ and above is considered suitable to make group inferences that are accurate enough.

iii) Operational Guide for Instructions (OGI)- OGI are the lesson plans used for teaching both the experimental and control groups. It consists of 4 major procedural steps that are sequentially and logically dependent on each other. The steps are as follows: Introduction, Exposition, Remediation and Summary/Evaluation. These lesson plans were validated by 3 experienced physics educators who found them to be adequate for teaching the selected topics in Senior Secondary Two (SS.2) physics curriculum. The trial test showed that the teachers had no problem in using the OGI and it produced an Inter-rater reliability values that ranged from 0.87 to 0.94 .

\subsection{Procedure for Data Collection}

The procedure was carried out in phases namely training, pre-testing, treatment and post- testing. There were 2 experimental and 2 control schools. 
Training Phase: This involved a 1-week training programme for the 4 regular physics teachers who do the teaching during the treatment period. For the purpose of this training the teachers were grouped to reflect the various groups of students they were to handle.

All the teachers prepared lesson plans on each of the heat-based concepts selected. These were scrutinized by the author (i.e. researcher). Each teacher presented four lessons each on the concepts based on his assigned roles. These lessons were observed and thoroughly discussed by all members of the research team during the training period. Hence, the experimental teachers in this study were very familiar with the experimental treatment.

Pre-testing Phase: This involved the administration of CST and PAT on the subjects.

Treatment Phase: The trained physics teachers commenced treatment after their pretesting session. During treatment, all the4 trained teachers applied what they learnt from the training session in teaching their various groups. For 3 weeks which the treatment lasted the researcher paid unannounced visits to the experimental and control schools thrice a week to monitor the activities of the teachers as well as determine how accurate and consistent they are in the operationalization of the treatment conditions.

Post-testing Phase: This involved the administration of PAT at the end of $4^{\text {th }}$ week of treatment.

\subsection{Experimental Group}

The peculiarity of treatment given to this group was that the group members were exposed to systematic (planned and organized) attributes of CASS. Before the commencement of the 6 weeks instruction, the physics teacher discussed with the group the procedure to be adopted. The discussion involved making the students aware of the following:

i) topics of which assessment of the 6 weeks instruction should be based;

ii) number of assessment scheduled for the period;

iii) topic to be covered by each assessment;

iv) date for each assessment; and

v) type of instrument (e.g. multiple-choice test, essay test, project, practical test etc.) to be used during each assessment.

In the course of the 6 weeks instruction, the physics teachers in the experimental group conducted the assessment of students in the group in line with the issues raised above.

\subsection{Control Group}

Students in this group were exposed to unsystematic (unplanned and unorganized) attributes of CASS. There were no discussion and planning whatsoever, involving teacher and students, on the procedure to be adopted as was the case with the experimental group. Students in this group, were NOT aware of the

i) topic of which assessment of the 6 weeks instruction should be based;

ii) number of assessment scheduled for the period;

iii) topics to be covered by each assessment;

iv) date for each assessment; and

v) type of instrument (e.g. multiple-choice test, essay test, project, practical test etc) to be used during each assessment. 


\subsection{Data Analysis}

The pos-ttest performance scores (at the cognitive level of remembering) were subjected to analysis of covariance using pretest scores as covariates. Graphical illustrations were also employed as post-hoc measures to disentangle significant interaction effects.

\section{Results}

Table 1 shows data from the analysis of covariance of physics performance at the cognitive level of remembering. The table shows significant main effects of treatment $\left(\mathrm{F}_{(1) 119)}=474.267 ; \mathrm{p}<0.05\right)$, cognitive style $\left(\mathrm{F}_{(1) 119)}=144.879 ; \mathrm{p}<0.05\right)$ and gender $\left(\mathrm{F}_{(1) 119)}=29.085 ; \mathrm{p}<0.05\right)$. It also shows two-way significant interaction effects of treatment and cognitive style $\left(\mathrm{F}_{(1) 119)}=56.358 ; \mathrm{P}<0.05\right)$.

Table 1: Summary of $2 \times 2 \times 2$ ANCOVA on the Post-test Performance scores of subjects according to treatment, cognitive style and gender on remembering of physics concepts.

\begin{tabular}{lrrrrr}
\hline Source of Variation & $\begin{array}{c}\text { Sum of } \\
\text { squares }\end{array}$ & DF & \multicolumn{1}{c}{$\begin{array}{c}\text { Mean } \\
\text { Square }\end{array}$} & F & Sign. of F \\
\hline Covariates & 1407.105 & 1 & 1407.105 & 114.682 & 0.000 \\
Pretest & 1407.105 & 1 & 1407.105 & 114.682 & 0.000 \\
\hline MAIN EFFECTS & 8994.408 & 3 & 2998.136 & 244.354 & 0.000 \\
\hline Treatment & 5819.101 & 1 & 5819.101 & 474.267 & $0.000^{*}$ \\
Cognitive Style & 1777.613 & 1 & 1777.613 & 144.879 & $0.000^{*}$ \\
Gender & 356.868 & 1 & 356.868 & 29.085 & $0.000^{*}$ \\
2- Way Interactions & 790.037 & 3 & 263.346 & 21.463 & 0.000 \\
Treatment x Cog. Style & 691.494 & 1 & 691.494 & 56.358 & $0.000^{*}$ \\
Treatment x Gender & 16.533 & 1 & 16.533 & 1.347 & 0.248 \\
Cog. Style x Gender & 42.912 & 1 & 42.912 & 3.497 & 0.064 \\
3- Way Interactions & 4.484 & 1 & 4.484 & 0.365 & 0.547 \\
Treatment x Cog. Style x Gender & 4.484 & 1 & 4.484 & 365 & 0.547 \\
\hline EXPLAIN & 11196.034 & 8 & 3199.504 & 114.062 & 0.000 \\
\hline RESIDUAL & 1361.933 & 111 & 12.270 & & \\
\hline TOTAL & 12557.967 & 119 & 105.529 & & \\
\hline * significant at $<<0.05$ & & & & &
\end{tabular}

The Multiple Classification Analysis, MCA (Table 2) reveals that students exposed to systematic attributes of CASS performed significantly better than their counterparts in the control group. The MCA also shows that analytical performance better than nonanalytical while females performed better than males. In all, the MCA reveals a multiple $\mathrm{R}$ squared value of 0.828 and beta values of $0.69,0.47$ and 0.17 for treatment, cognitive style and gender respectively. 
Table 2. Multiple Classification Analysis (MCA) of the Post-test Performance scores of subject according to treatment, cognitive style and gender on the remembering of physics concepts.

\begin{tabular}{|c|c|c|c|c|c|}
\hline \multicolumn{6}{|c|}{ Grand Mean $=32.78$} \\
\hline Variable + Category & 'N' & Unadjusted Deviation & 'Eta' & $\begin{array}{c}\text { Adjusted } \\
\text { Independent } \\
\text { Deviation }\end{array}$ & Beta \\
\hline \multicolumn{6}{|l|}{ Treatment } \\
\hline 1. Systematic Attributes (SA) & 68 & 7.14 & & 6.5 & \\
\hline $\begin{array}{l}\text { 2. Unsystematic Attributes } \\
\text { (UA) }\end{array}$ & 55 & -8.44 & 0.76 & -7.68 & 0.69 \\
\hline \multicolumn{6}{|l|}{ Cognitive Style } \\
\hline 1. Analytic (A) & 66 & 5.29 & & 4.38 & \\
\hline 2. Non-analytic $(\mathrm{N})$ & 54 & -6.46 & 0.57 & -5.35 & 0.47 \\
\hline \multicolumn{6}{|l|}{ Gender } \\
\hline 1. Male & 72 & -0.89 & & -1.45 & \\
\hline 2. Female & 48 & 1.33 & 0.11 & 2.18 & 0.17 \\
\hline Multiple $\mathrm{R}^{2}$ & & & & & 0.828 \\
\hline Multiple & & & & & 0.910 \\
\hline
\end{tabular}

The researchers used graphical illustration to explain the significant two-way interactions between treatment and cognitive style. This is illustrated in Figure 1. The figure shows ordinal interaction and all the students exposed to systematic attributes of CASS performed better than their counterparts in the control group irrespective of their cognitive style grouping. In addition, the figure shows that the differential effect of treatment on students knowledge of physics concepts was such that the impact was more on non-analytical than analytical subjects.

\section{Discussions and Conclusion}

The result that treatment had significant effect on students' remembering of physics concepts is explicable considering the views of Okpala and Onocha (1995) that the act of providing a student with advance information (as stated in attributes of CASS) on the topics which the assessment of an entire educational programme should be based and the content areas to be covered by specific assessment as well as the type of assessment that will involve is likely to

i) motivate the student's learning and help clarify instructional objectives;

ii) enable the student to tailor his study towards the specific content area to be covered by each assessment; and

iii) make student to be more organized and prepared towards improving his study habits.

The significant main effect of student cognitive style on knowledge of physics concepts shows that analytical subjects performed better than the non-analytical subjects on knwledge of physics concepts. This seems, that student's performance in physics is a function of the extent to which the student is analytically inclined as was stated by Messick (1970) and Aghadiuno (1992). The significant differences in the performance of the cognitive-style group could be attributed to the nature of the student groups. As indicated by Moss and Sigel (1963) analytical students exhibit the tendency to split stimulus into discrete entities and then differentiate them separately as against the nonanalytical students whose categorization and response are based on a whole. This reported significant effect of students' cognitive style on knowledge of physics concepts corroborates the study findings of Shymanshy and Yore (1980) and Ughamadu (1990). 
The significant main effect of gender on students knowledge of physics concepts in favour of female students corroborates the findings of Balogun and Olanrewaju (1985) and Deboer (1986). These results seem explicable considering the study result of Adeoye (2000) that females would achieve better than males when test items are based on physics contents/concepts that require learners of low numerical ability while the reverse would be the case when the test is based on physics concepts/contents that require learners of high numerical ability.

The significant interaction effect of treatment and student cognitive style on knowledge of physics concepts as shown in Figure 1 show that the positive effect of treatment on physics performance at this level is sensitive to students' cognitive style. The sensitivity is such that the effect is more on non-analytical students than on the analytical ones irrespective of the result that both analytical and non-analytical students seem to significantly improve their performance when exposed to the treatment conditions.

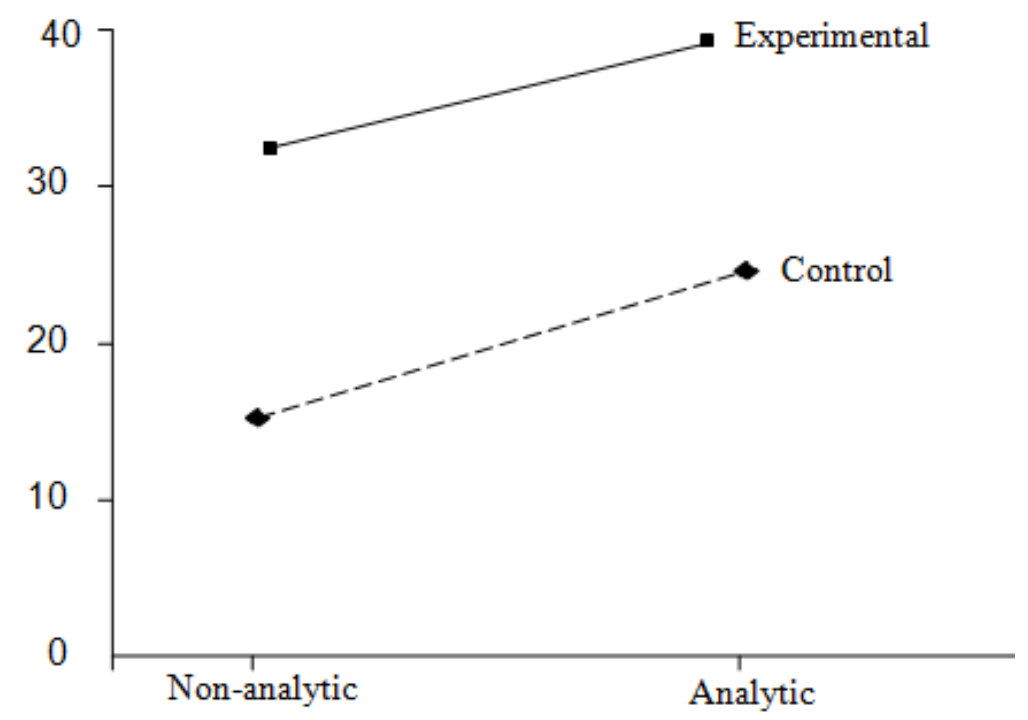

Figure 1. Graphical illustration of interaction effect of treatment and cognitive style on remembering of physics concepts.

In all, the independent variables, when taken together could explain $82.8 \%$ of variation in students' knowledge of physics concepts-a level of explanation that is considered significant $(\mathrm{p}<0.01)$. The treatment tends to contribute most to the explanation (48\%); followed by cognitive style (22\%); while gender is the least contributor $(3 \%)$.

In the light of the entire study results and the associated discussion, the researchers share the view that as part of the efforts to improve students remembering of physics concepts the following points should be noted for implementation.

i) Principals, head teachers and supervisors of schools should cooperate to ensure that practicing physics teacher plan and organize the various assessments for their students as suggested in the present study;

ii) Principals, head teachers and supervisors of schools should ensure the adoption of CASS attributes in their choice of any instructional delivery methods in the teaching of physics. 
iii) The Nigerian Science Teachers' Association (STAN), Physics Teacher Association and other relevant academic societies responsible for teaching of physics should endeavour to popularize the adoption of CASS characterized instructional delivery strategies in the teaching.

iv) Teachers should not discriminate between boys and girls, analytical and nonanalytical as well as any possible cognitive style-gender combinations while using systematic attributes of CASS;

v) All genuine efforts should be made to remove all sources of gender bias in physics since researchers (e.g. Kelly 1981; and Okpala and Onocha 1988) attribute gender differences in physics achievement partly to environmental and situational differences as against genetic factor.

\section{References}

Adeniyi, E. O. (1996). The influence of cultural and gender factors in science understanding of science content. Paper presented at the $37^{\text {th }}$ Annual Conference of the Science Teachers Association of Nigeria in Akwa Ibom State, 12-17 August.

Adeoye, F. A. (1998). Assessment procedure, cognitive style and gender as determinants of performance in hierarchical cognitive tasks in physics. A paper presented at the Institute of Education Staff Seminar.

Adeoye, F. A. (2000). Assessment procedure, cognitive style and gender as determinants of students performance in hierarchical cognitive tasks in physics. Unpublished Ph.D. Thesis, University of Ibadan, Ibadan, Nigeria.

Aghadiuno, M. C. K. (1992). A path-analytic study of cognitive style, understanding of Science and attitudinal variables as correlates of achievement in secondary school Chemistry. Unpublished Ph.D Thesis, University of Ibadan, Ibadan, Nigeria.

Balogun, T. A. (1994). Gender issues in the teaching of Science, Technology \& Mathematics. In S. Y. Erinosho (ed) Perspectives on women in science and Technology in Nigeria. Nigeria: Sam Bookman educational and Communication Services. $47-51$

Balogun, T. A. and Olanrewaju, A. O. (1985). The effects of instructional objectives and hierarchically organized learning tasks on students' problem solving skills. Journal of Science Teachers Association of Nigeria. 23(1\&2), 191-198.

Deboer, G. E. (1986). Perceived science ability as a factor in the course selection of men and women in College. Journal of Research in Science and Technology. 23(4), 343352.

Federal Government of Nigeria (FGN) (1998). National Policy on Education, 3rd edition, (Nigeria: NERDC Publications)

German, P. J. (1988). Development of attitude towards science in school assessment. Journal of Research in Science Teaching. 28(8), 689-703.

Hurd, P. D. (1983). State of pre-college education in science and Mathematics. Science Education. 227-234

Iloputaife, E. C. \& Nworgu, B. G. (2003). Analysis of restructuring alternative concepts of physics students using analog and a five-step-conceptual change instructional models. In M.A.G. Akale (Ed), from Science, Technology and Mathematics 
Education for Sustainable Development in Africa (Ibadan-Nigeria, Science Teachers Association of Nigeria Publications), 405-408.

Kelly, A. (1981). Science achievement as an aspect of sex roles. In Kelly, (ed.) from the Missing Half: Girls and Science Education (Manchester: Manchester University Press), 73-84

Messick, S. (1970). The criterion problems in the evaluation of instruction assessing possible not just intended outcomes. In Wittrock, M.C. and Wiley, D. (eds), The Evaluation of Instruction: Issues and Problems. New York: Holt, Rinchart and

Moss, A. and Sigel, I. E. (1963). Cognitive style implication for learning and instructions. Psychology in School, (8), 152-161.

Obe, E. O. (1983). A survey of the attitudes of some Lagos secondary school teachers towards continuous assessment. Journal of Research in Curriculum, 1(1), 9-16.

Obioha, N. E. (1987). Declining trends in students' choice of science and technology. $28^{\text {th }}$ Science Teachers Association of Nigeria Annual Conference Proceedings, 1624.

Ojerinde, B. and Falayajo, W. (1984.) Continuous Assessment a New Approach. University Press Ltd. Ibadan, 1-7.

Okpala, N. P. and Onocha, C. O. (1994). Teacher assessment of a new physics curriculum for Nigeria Secondary schools. Olumo Journal of Education 1(2), 35-40.

Okpala, N. P. and Onocha, C. O. (1995) The effects of systematic assessment of procedures on students achievement in Mathematics and science subjects. UNESCO-AFRICAN (A Six-Monthly Journal of the Dakar UNESCO Regional Office in Africa), (10), 55-6

Onocha, C. O.; Okpala, N.P. and Offorma, G. (1995). Education of Women and girl's study of equity in eastern Nigeria. A study commissioned by the Regional Office of UNESCO/BREDA in Africa, Dakar, Senegal.

Orji, A. B. C. (1998) Effects of problem-solving and concept-mapping instructional strategies on students' learning outcomes in physics. Unpublished Ph.D. thesis, University of Ibadan, Ibadan.

Onwioduokit, F. A. (1998). Communicating physics through materials: a case study of Akwa Ibom State Government Science Colleges. In A. O. Olarewaju (Ed), Communicating Science, Technology and Mathematics. (Ibadan-Nigeria, Science Teachers Association of Nigeria publications), 283-287.

Shymansky, J. and Yore, L. (1980). A study of teaching strategies, cognitive development and cognitive style as they relate to students achievement in science Journal of Research in Science Teaching, 17(5), 369-382.

Ughamadu, K. A. (1990). Interactive effect of formative testing and cognitive style on students' learning outcome in senior secondary school chemistry. Unpublished Ph.D. thesis, University of Ibadan, Ibadan. 